\title{
Building Relationships between Schools and Communities’ Agencies: Crafting a Programmatic Proposal
}

\author{
Imran Shaari, Shu-Shing Lee \\ Office of Education Research, National Institute of Education, Nanyang Technological University, \\ Singapore City, Singapore \\ Email: \{imran.shaari, shushing.lee\}@nie.edu.sg
}

Received April 26 ${ }^{\text {th }}, 2012$; revised May 24 ${ }^{\text {th }}, 2012$; accepted June $8^{\text {th }}, 2012$

\begin{abstract}
Building relationships are increasingly important because schools cannot act alone in the 21st Century to make learning relevant to learners. It is also pointed out that a good education requires diverse environment-where learners can benefit from its unique qualities. In order to understand how relationships can be established without diluting the qualities, this paper proposes research collaborations between schools and communities' agencies. Three sub-units that focus on research, policy and social are proposed. They are intended to co-inform schools and communities' agencies in preserving unique qualities afforded by the entities for learners to benefit.
\end{abstract}

Keywords: Programmatic Proposal; Relationships; Schools; Communities; Formal-Informal Learning

\section{Introduction: Research Aim and Background}

This paper proposes future directions pertaining to bridging learning within schools and communities' agencies with the view to benefit diverse learners. Diverse learners include learners with different talents and learning abilities (for example, low or high abilities). The Ministry of Education's (MOE), Singapore, definition of diverse learners: Special, Express, Normal (Academic) and Normal (Technical) (MOE, 2011a) is used. The definition is suitable because it emphasizes customized curricular that matches individual learning abilities and interests. The definition has provisions in extending the customized curricular to include activities valued by the larger communities. School environments include classroom and activities spearheaded by schools or the schools' agents, such as the MOE and schools' departments. Communities' agencies are associated with out-of-school environments where they are largely about communities and activities generated outside classroom time-for example Co-Curricular Activities (CCA) (MOE, 2011b) — where schools or their agents have less influence on learners' participation, performance, and assessment. Learning in school environments focuses on structured content (explicit knowledge), extrinsic motivation, and strict assessments while learning in out-of-school contexts is characterized by less structured activities and opportunities to develop tacit understandings by allowing more exploring, messing around, and tinkering.

For ease of discussion, we adopt Thomas and Brown (2011) broad definition that associates school environments with formal learning and out-of-school environments with informal learning. These connotations are used interchangeably in this paper. Importantly, the assumption is that both formal and informal contexts have relative benefits and it is important to preserve their uniqueness. The focus is on structural relationships that link learning in formal and informal contexts to benefit diverse learners. Structural relationships refer to linkages between schools and external entities and how they are organ- ized.

The focus on structural relationships is motivated by trends generated in education research and research grant proposals in Singapore. The unique opportunities of collating and analyzing about 120 research proposals from 2009-2011 provide insights of researchers' and schools' interests and practices. These research proposals are administrated by the Office of Education Research Office in Nanyang Technological University, Singapore. Although schools have tried to embed 21st century literacy and dispositions into the curriculum through CCAs (MOE, 2011b), our findings suggest that there is an overemphasis on content knowledge in classroom learning. The instructional orientation used in schools is inconsistent with the softer skills of 21st century literacy (Hargreaves, 2003). In-schools and outof-school learning are parts of Singapore's education curriculum but these components are mostly seen as disparate. Few attempts are made to understand the dialectics between them to achieve holistic learning. Furthermore, existing studies also tend to focus on either learning in formal or informal contexts without investigating how learning in both contexts co-informs to provide different learning opportunities for diverse learners. Hence, there is a need to research into how bridges can be formed between in school and out-of-school learning by leveraging on structural affordances that schools may establish with communities. The focus on structural relationships between schools and external entities tries to achieve holistic learning by offering:

- Opportunities to leverage strengths from schools and outof-schools contexts;

- New research paradigm as knowledge intertwined from both contexts;

- Unique learning experiences such that the sum is greater than the total of the parts.

These benefits are fitting for the current global environment. Particularly, in some local contexts where a vision such as the one below takes center stage: 
"Between academic achievements and values, it must not be 'either/or'. We should strive to achieve both.” Heng Swee Keat, Singapore Education Minister (Ng, 2011).

From this excerpt, it can be inferred that learning in the 21st century is not about focusing on either academic achievements or developing 21st century dispositions. Rather, 21st century learning needs a holistic, student-centered approach that embraces both academic achievements (content knowledge) as well as soft skills.

To balance content knowledge with the learning of 21st century literacy and dispositions, propositions are made to bridge students' learning in classroom with learning in out-of-school contexts (Thomas \& Brown, 2011), such as sports activities and learning with communities. The benefit of bridging formal and informal learning includes holistic learning experiences that embrace a range of dispositions, attitudes, skills, and knowledge. It is about offering our learners with opportunities of expanded learning spaces that are boundary-less and diverseabilities centric. While schools have the infrastructure (for example, pedagogy content knowledge, information and communications technology) in propelling students to excel in academic achievements, the communities may offer contexts in which that academic excellence can be practiced in-sync with society expected values. By establishing links with external entities, community direct participation and ownership of students' outcome are attainable.

While schools have their traditional mandates, opportunities in out-of-school learning can be brokered by schools. Thus, this paper envisages a set of principles that different stakeholders, like educational practitioners, policy makers, parents, and the wider communities, could use as guides to understand and build upon the learning that occurs from both contexts. It would like to explore how relationships between formal and informal contexts can offer alternative opportunities, expanded learning contexts, and broaden participation for diverse learners. The different avenues of learning, as evidenced by the following findings, can be viewed as impetus in moving an education system from great to excellence (Barber, Chijioke, \& Mourshed, 2010) - because of these encouraging findings:

1) The relationships between formal and informal learning environments have assisted in engaging learners to the formal academic concepts taught in schools (National Research Council, 2009). They have increased students' motivation to acquire knowledge from outside school boundaries. This is particularly critical in teaching subjects that require a more holistic exposure compared to just memorizing facts (Kytta, 2002). If delivery methods have factored different contexts and multiple scenarios, learners' experiences are enhanced (Nasir \& Hand, 2008; Kapur, 2008). To achieve this, active involvement by communities are important in offering authentic environments - where interest and engagement in learning can be sustained (Barron et al., 2010).

2) The relationships have assisted in developing dispositions desired by contemporary organizations (Brown \& Thomas, 2008). In game-based learning, for example, students are exposed to skills such as team bonding, developing strategies on the fly, filtering critical information, and making the best of a situation (Barab \& Duffy, 2000). Since schools may have constraints and it is not realistic to assume that teachers are able to teach all the skills needed, partnerships with practitioners and communities can assist in acquiring these skills through learners' self-initiated and interest-driven learning (Shaffer et al.,
2005).

3) The relationships may create opportunities to network among learners, schools, and communities. For schools, the benefits include access to communities' infrastructure (that is, experts, established connections, specialized technology and techniques). In turn, early exposure to practitioners' artifacts is increased. Importantly, by interacting with practitioners, students can observe passion and excellence directly-a critical process in acquiring tacit knowledge (Nonaka \& Konno, 1998). For communities, the relationships are a resource to identify budding talents. Identified talents can be groomed to ensure communities' continued success and existence. Thus, the relationships assist in retaining talents locally and enable communities to contribute back to the society.

Thus, we agree that understanding relationship building is a resource (Jensen, 2003). While there are studies on formal and informal learning environments, only recently have researchers begun to analyze the connections among learning experiences in different contexts (Banks et al., 2007; Bell et al., 2009). To understand the relationships and for the benefits to be realized further, first, we highlight some trends identified in our education system.

\section{Evidence from Existing Projects: Trends of Formal and Informal Education in Singapore}

The trends reported are partly informed by literature and largely influenced by our projects administered by the Office of Education Research in Nanyang Technological University, Singapore. The projects investigate integration of formal and informal learning environments in Singapore. Range of local and overseas participants from education administrators, teachers, principals, coaches, students, and parents were interviewed. Additionally, joint events were observed and study visits were conducted. From preliminary evidence collected, we discovered the following trends in Singapore pertaining to how formal education orientates itself with informal education and vice versa. For our analysis, we view CCA as a form of informal activities.

- There were tendencies of cramming informal activities in the already compact formal activities. For instance, it was not uncommon that schools had extended hours (that is, after schools hours and during schools holidays) to conduct CCA activities. This approach might not be productive because staff and students were overtaxed which reduced learners' holistic experience. Rather than integrating CCA activities into the normal school hours. CCA activities appeared to be an "add on" component. However, we also recognize that some CCA activities, such as dance and sports, need to be conducted after school hours and during holidays to ensure students are ready for competitions and performances.

- There were tendencies in filtering informal activities and choosing those that conformed or "fitted" with schools ethos. The filtering processes were performed on the basis of a set of values determined by the schools. Thus, learners' and communities' wants were overshadowed if they were misaligned from the schools' vision. For instance, schools formulated niche CCA programs in attracting the "right" types of students to increase academic performance indicators were noted. There were also instances when schools only conducted CCAs where they had sufficient resources, 
such as teachers-in-charge, facilities, and coaches. CCAs offered are, hence, not considered from the perspective of students' interests. This leads to a misalignment between CCAs offered in schools and the ones that students are interested in.

- There were tendencies to formalize informal activities to draw maximum quantifiable benefits from them. Attendance taking and rote instructions approaches, for example, in perfecting specific parts of the activities were not uncommon. The assumption was if these approaches worked effectively in formal settings, they might also work in informal settings. However, caution is needed because such approaches may actually dilute informal settings' benefits as learners' learning trajectory in the contexts differs (Barab \& Duffy, 2000). The social construals afforded by the formal and informal settings are for learning skills and experiences that are complementary but not similar.

- There were tendencies to assess informal education activities by using formal benchmarking systems. The assessments included points systems and tangible rewards. The assessments were meant as motivational factors and extrinsic rewards (for example, grades, medals, money) to motivate learners to some degree (Lepper et al., 1973). However, they must not be viewed as the ultimate objective, which appeared to be the case now because there is lack of continuity in some of the informal programs. For example, interests nurtured in schools are not pursued as a lifelong endeavor when students graduated. Furthermore, excellence achieved in informal activities can become one of the criteria for admission to schools. In this manner, the intrinsic motivation of participating in informal activities becomes diluted. Students, encouraged by their parents, begin to participate in informal activities that award them with more "points".

In summary, the trends suggested that schools have tried to subsume informal activities by treating them as formal. Likewise, out-of-schools activities appeared to be more formalized. This is a healthy indicator because it suggests that values afforded from both contexts are appreciated. However, if left unchecked, the trends may lead to over-institutionalization. These practices in informal contexts may also imply that although schools recognize the usefulness of informal learning, they seem unsure about how to manage or maximize learning experiences afforded in the informal context. Thus, they begin to use familiar practices from formal learning and impost them on the informal. This may not be the best approach because the objectives of learning in formal and informal contexts are different.

We envisage that it would be beneficial to understand productive relationships between formal and informal learning where values from both contexts are not diluted and hence becoming unproductive, but leverage upon instead. We hope to avoid obscuring the values in one context when pursuing for excellence in the other. We are cautious to prevent the values becoming diluted as a result of heavy handedness on one context at the expense of the other by different stakeholders (that is, parents, policy makers, schools).

\section{Research Questions: Reflections of the Trends and Theoretical Grounding}

From the above trends, some practical questions are: "Do we want the trends to continue? Do we believe that they are the best way forward in improving Singapore education further?” Bowen and Bok (1998) and The Life Center (2007) insightfully point out that a good education requires a diverse environment-where learners can benefit from its unique qualities. In the context of Singapore's education system, its unique quality relates to having both a formal and informal learning component as part of its curriculum. If the trends are institutionalized, then, "How convinced are we that the distinct values afforded from the contexts will be preserved?” Thus, the paper is seeking ways forward to address this overarching key question:

- What are the guiding principles in establishing productive relationships between formal and informal contexts? Productive refers to:

o Ensuring values afforded by the contexts are preserved;

o Enabling diverse learners to synthesize the values afforded by the contexts and to make the best out of them.

From our pilot projects, we noted that the phenomena of establishing bridges between learning in school and out-of-school contexts generated interest and participation from the larger communities (for example, service providers, practitioners) and stakeholders beyond the formal education systems (for example, MOE, schools). Thus, another overarching key question is:

- How should we appropriate the principles to benefit different stakeholders (that is, schools, ministry, researchers, parents, teachers, learners and communities)?

Research on learning in formal settings is maturing and has enabled the production of an authoritative document (Duschl et al., 2007). In contrast, it would be difficult to locate a similar authoritative document on informal education (Bransford et al., 2005). There are several proponents of informal learning like John Seeley Brown but study on informal learning settings is still in its infancy. Fortunately, in Singapore, we witness admirable efforts of learning in the formal (that is, schools) and informal (for example, CCAs) contexts that contribute to learners' experience. However, we are not sure how to strike a balance between the two contexts. Learning in formal and informal settings promotes different values and approaches, and their activities are organized in distinctly different ways. Hence, the difficulty of investigating relationships between the contexts appears daunting. One could wait till the study on informal learning contexts becomes widespread and then investigate how the relationships between the two contexts manifest. This may not be the best approach because the trends on relationships between formal and informal learning are already prevalent. Without proactive initiatives, misguided principles might become ingrain which in turn make reversing them (if needed to), a difficult task.

We propose qualitative empirical data to be collected first. An induction approach is preferred because Singapore education system of integrating comprehensive set of out-of-schools activities (that is, different CCA types) as part of structured formal curriculum is unique. A theoretical understanding emerging from the data through several rounds of pilots study would likely be more effective than to develop hypothesis from literature. The literature might be less relevant to Singapore context (for example, multicultural, tripartite systems, CCA). Nevertheless, we are aware that informal learning may manifest in different approaches, such as incidental learning (Harrison, 1954), non-formal learning (Hager \& Halliday, 2009) and experiential learning (Evans, 1993). They are useful approaches, which provide different insights on how informal learning can be enacted. These approaches focus on learning experiences 
and techniques used, most often, from the non-traditional education institutions, and how they can assist in translating lessons learnt as utilities for formal settings. We would like to adopt a broader approach.

To start, we follow Barron's (2006) concepts of learning ecology, which is defined as the set of contexts found in physical or virtual spaces that provide opportunities for learning (see Figure 1). "Each context is comprised of a unique configuration of activities, material resources, relationships, and the interactions that emerge from them”, (p. 195). Barron's concept suit us because our objective is to investigate issues pertaining to bridging learning between school and out-of-school environments with the view to benefit Singapore's diverse learners. In that regard, out-of-school includes the life spaces of home, school, community, work and the neighborhood. Importantly, Barron's concept emphasizes individual differences in learning outcomes and their relationships to access and use of resources across contexts. Similarly, we believe that diverse learners require different degrees of attention by schools and out-ofschool agents. For instance, in the Singapore context, "express [academic stream] students need less scaffolding in relation to content subjects and have more time in appreciating the CCA activities as opposed to the normal stream students," claimed a teacher. And "supporting parents will definitely make a difference with regard to CCA participations", she continued.

Unfortunately, manifestation of the relationships formed between formal and informal contexts is not well understood. Are we to assume that the degree afforded by the relationships in enhancing our diverse learners is the same across different contexts?

The assumption is that, at the least, there is a set of two distinct arrows in operation for each context: one at structural and the other at micro level, and the "thickness" or the degree of these arrows varies from one context to another and is influenced by the type of learners. Experiential, incidental, and non-formal learning are viewed as micro level interventions. They are teacher intensive and attempt to transfer cognitive learning experiences across contexts and may not differentiate students' abilities.

Extending Barron's concept (See Figure 2), our key components are: structural relationships and diverse students. The key study area would be in determining how the former influence diverse groups of students. To do so, it is important to investigate influential elements (that is, shared resources, ideological, affective, and funding) (Johnson \& Chrispeel, 2010)—-that bind the relationships because schools and the communities serve different goals (Winston, 1998). While schools' purpose is to increase literacy and to promote desirable social values (Winston, 1998), communities (for example, vendors) may seek material wealth and have different agendas from schools (Ireland \& Hitt, 2005). Additionally, while the Ministry has direct administration responsibility over schools, diverse stakeholders in the formal-informal contexts propel the communities' interest. By investigating the relationships' elements, it is an important step towards understanding how structural relationships between schools and communities operate, which in turn influence the diverse learners.

\section{Methodology: Formal/Informal Research Collaboration}

To confront the phenomena (Figure 2) directly, we propose research collaboration. The purpose is to develop and test principles about structural relationships between formal and informal learning systems with the view of enabling productive outcomes for diverse learners. The collaboration envisages:

- The first formal/informal learning collaboration in Asia that brings together representatives from a broad range of fields to interact (within Singapore and across the region) and raise current issues for the collaboration to address to remain relevant. It maintains a web of eco-systems in formal-informal contexts to anticipate change and address anomalies that are aligned with global and local circumstances.

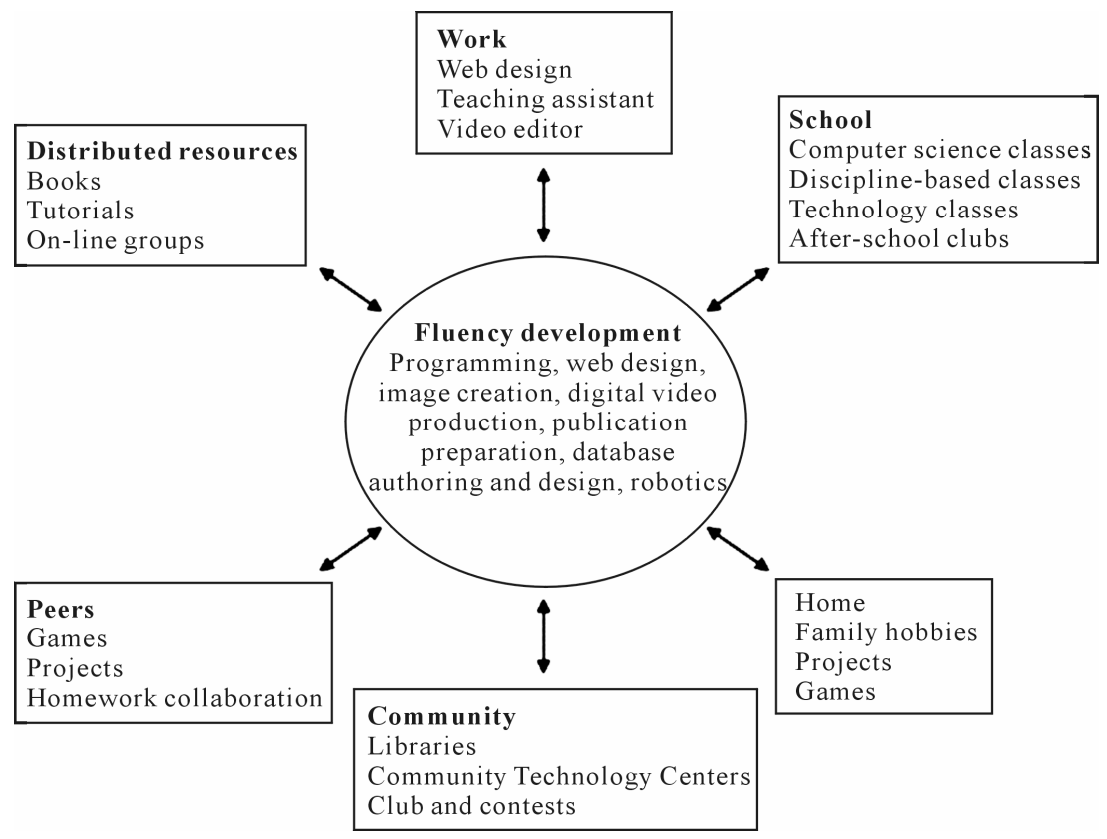

Figure 1.

A learning ecology (adapted from Barron, 2006). 


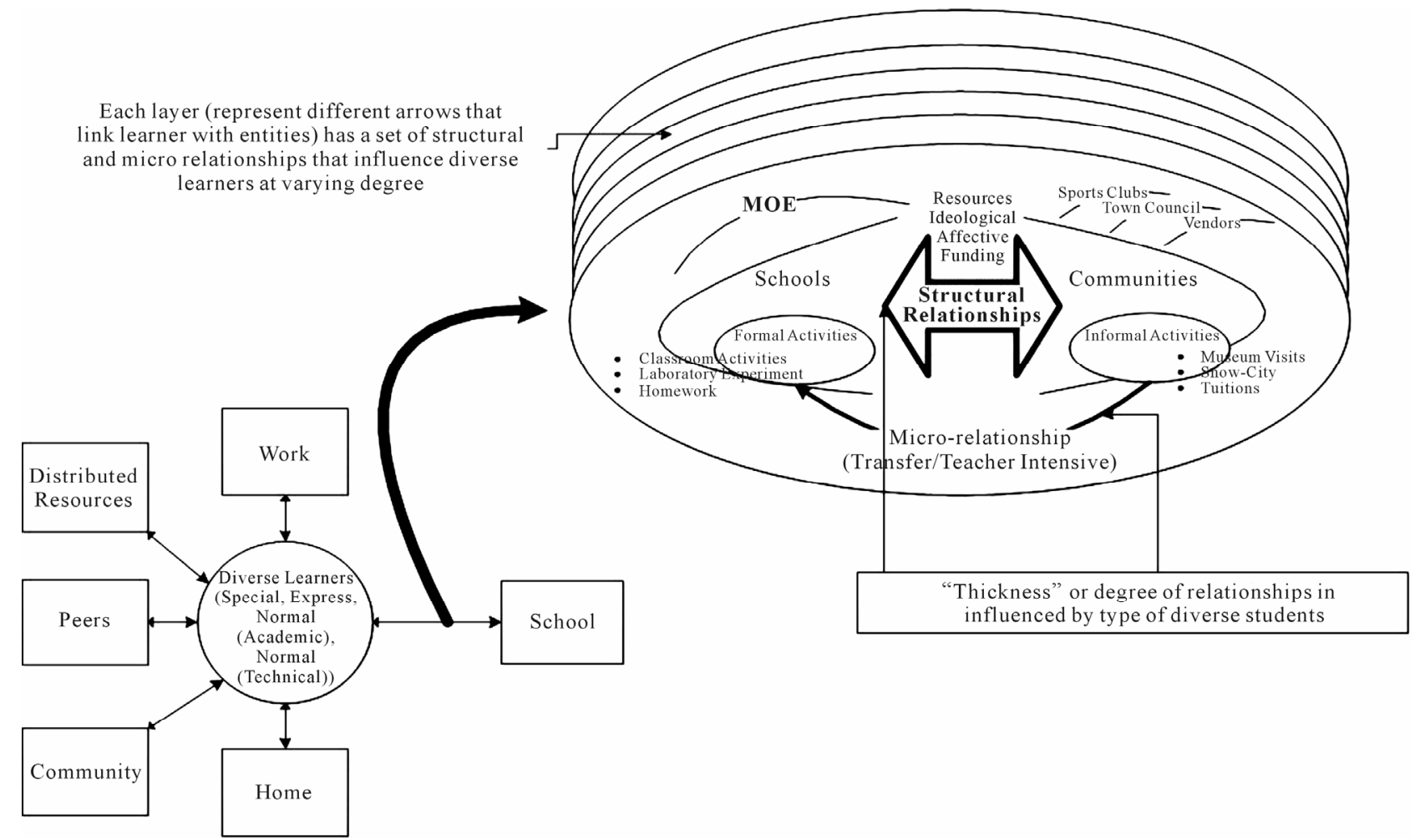

Figure 2.

A framework showing a set of relationships plus related activities that influence diverse learners in a learning ecology system.

A collaboration effort is appropriate because Singapore's education curriculum is unique as it has an integrated in school and out-of-school learning component. The effort would be a mechanism to:

1) Investigate different methodological approaches that emphasize participation from multiple stakeholders. Scenarios where out-of-school practitioners lead the research with consultation from the researchers are not impossible.

2) Derive empirical based findings for translation to policies in emerging manner that appreciate operational dynamic concerns without compromising long term strategic objectives. The collaboration would assists to promote flexible policies that are sensitive to the needs of diverse learners with the view that no students should be left behind.

3) Establish ecology of stakeholders in school and out-ofschool contexts to enable bridges between learning across school and out-of-school environments. The collaboration would act, as facilitator that linked different contexts that otherwise is disparate.

Many centers in the National Institute of Education-NTU, Singapore exist, but most of them concentrate their work on one particular field. For instance, Centre for Research in Pedagogy and Practice (CRPP) (CRPP 2011) is focused on pedagogy and practices related to curriculum, instruction, assessment, teachers' professional development, and students' characteristics. Whereas Centre for Arts Research in Education (CARE) (CARE 2011) aims to promote education in and through the arts in partnership with like-minded individuals and organizations.

We propose collaboration efforts that work closely with diverse communities to include individuals and organizations that are both like-minded and otherwise. The collaboration will devote itself in offering pragmatic help that truly benefit diverse learners. It recognizes individuals' talents and values divergent participation from the communities. Thus, for the collaboration to be operationally effective, three interrelated foci are proposed: Research, Policy and Eco-Systems.

\section{Research Focus}

It aims to develop multiple methodologies to investigate how links between formal and informal learning environments can be synthesized and established. Rationale for developing methodologies can be informed by literature and understanding how people learn across different formal-informal contexts and domains. Some relevant guiding questions (but not limited) to include:

- What roles do organizations, educational institutions, and communities play to enable research about learning in formal and informal environments?

- How do research about relationships between formal and informal environments impact students?

- How do theories and methods drawn from either or both formal and informal environments inform models of relationships between both environments?

\section{Policy Focus}

It aims to foster connections between research and policy to enable collaborations with individuals and institutional partners as well as promote evidence-based improvements (both theoretical and practical) enabled by policies to meet diverse learners' needs. Some relevant guiding questions (but not limited) to 
include:

- How do policies informed by research define and appropriate relationships between formal and informal learning environments to address different stakeholders' expectations?

- How do policies informed by research enable interventions to occur in schools to translate, experiment, and validate school practices that are enabled by relationships between formal and informal learning?

- How do policies informed by research spread evidencebased practices across schools to enable holistic learning in both formal and informal environments? How do these evidence-based practices impact student outcomes?

\section{Eco-Systems Focus}

It aims to collaborate and congregate multiple stakeholders in formal and informal learning environments to establish a common belief that balanced learning approaches are critical in educating learners for the contemporary society. Multiple stakeholders collaborate and work together as a functional whole to enable mutual benefits for diverse learners. Some relevant guiding questions (but not limited to) include:

- How do relationships between stakeholders in formal and informal environments evolve to establish a balanced and common belief about learning in both environments?

- How are relationships between stakeholders in formal and informal environments negotiated to enable productive designs for balanced learning?

- How do the attributes, strengths, and characteristics of formal and informal environments co-inform each other to transform teaching and learning practices?

- How do the attributes, strengths, and characteristics of relationships between formal and informal environments shape the learning experiences and outcomes of diverse learners?

- How can relationships between stakeholders in formal and informal environments enable transformations to assessment systems that recognize different learning experiences, achievements, and outcomes?

Together, the foci synthesize to create a participatory research culture between researchers, policy makers, schools, and other stakeholders in communities to establish relationships and a balanced learning experience in formal and informal environments. The foci collectively work towards an evidencebased transformation of teaching and learning practices that concentrate on developing diverse students' content knowledge and dispositions.

\section{Expected Deliverables}

The collaboration expected deliverables include:

- A set of principles for schools and communities in establishing productive relationships that benefits diverse learners and provide holistic learning experiences that emphasize literacy and dispositions.

- A set of principles in guiding researchers, schools and communities to develop inclusive, long-term relationships that appreciate contributions beyond research, policy, and communities.

- A set of mechanisms in enabling schools and communities to customize their efforts for diverse learners' needs and expectations.

- A set of principles that systematically guides how schools can benefit from the communities and vice-versa (Mulford, 2008). Past study has focused on uni-directional of schools benefitting from the community. The collaboration would like to follow Mulford's suggestions to include how communities can benefit from schools by the relationships.

\section{Conclusion}

Education needs to consistently evaluate itself to stay relevant to changing times. As we move into the 21st century, there are increasing efforts to provide students with holistic education that focuses on values and character development. In line with the vision of holistic education (MOE Speech, 2011), we recognize that one way to prepare students for the 21st century is to engage schools, researchers, policy makers, and communities in understanding the value of learning in formal and informal contexts to develop base literacies and dispositions. We recognize that balanced participation in classroom learning and informal activities, such as CCA, can be one means of achieving this kind of balanced learning. Productive linkages can be formed to enable different learning experiences for diverse learners.

Education is accountable to many stakeholders. Thus, in the proposal for this research collaboration, specific foci by different stakeholders, like researchers, policy makers, schools, are synergized to create a multi-prong participatory research effort. Hopefully, by engaging different stakeholders in research, an effective strategy that embraces different views of formal-informal relationships is developed to move towards a balanced, holistic way of learning.

\section{Acknowledgements}

We thank Professor David Hung (Office of Education Research, National Institute of Education, Singapore), Professor Bill Mulford (University of Tasmania, Australia) and Professor Kristiina Kumpulainen (University of Helsinki, Finland) for their constructive feedbacks in strengthening this paper.

\section{REFERENCES}

Banks, J. A., Au, K. H., Ball, A. F., Bell, P., Gordon, E. W., Gutierrez, K. D., Zhou, M. et al. (2007). Learning in and out of school in diverse environments: Life-long, life-wide, life-deep. Seattle, WA: The Life Centre.

Barab, S., \& Duffy, T. (2000). From practice fields to communities of practice. In D. Jonassen, \& S. Land (Eds). Theoretical foundations of learning environments (pp. 25-55). Mahwah, NJ: Lawrence Erlbaum Associates.

Barber, M., Chijioke, C., \& Mourshed, M. (2010). Education: How the world's most improved school systems keep getting better. London: McKinsey \& Company.

Barron, B. (2006). Interest and self-sustained learning as catalysts of development: A learning ecology perspective. Human Development, 49, 193-224. doi:10.1159/000094368

Barron, B., Walter, E. S., Martin, K. C., \& Schatz, C. (2010). Predictors of creative computing participation and profiles of experience in two Silicon Valley middle schools. Computers and Education, 54, 178189. doi:10.1016/j.compedu.2009.07.017

Bell, P., Lewenstein, B., Shouse, A. W., \& Feder, M. A. (2009). Learning science in informal environments: People, places, and pursuits. Washington DC: National Academies Press.

Bowen, W., \& Bok, D. (1998). The shape of the river: Long term consequences of considering race in college and university admissions. Princeton, NJ: Princeton UP. 
Brown, J. S., \& Thomas, D. (2008). The gamer disposition. URL (last checked 17 January 2012).

http://blogs.hbr.org/cs/2008/02/the_gamer_disposition.html

Bransford, J., Vye, N., Stevens, R., Kuhl, P., Schwartz, D., Bell, P. et al. (2005). Learning theories and education: Toward a decade of synergy. In P. Alexander, \& P. Winne (Eds.), Handbook of educational psychology (2nd ed., pp. 1-95). Mahwah, NJ: Erlbaum.

CARE-Centre for Arts Research in Education (2011). URL (last checked 27 January 2012).

http://www.nie.edu.sg/research-centres/centre-arts-research-educatio $\mathrm{n}$

CRPP—Centre for Research in Pedagogy and Practice (2011). URL (last checked 11 March 2012).

http://www.nie.edu.sg/research-centres/centre-research-pedagogy-pra ctice-crpp

Duschl, A. R., Schweingruber, A. H., \& Shouse, W. A. (2007). Taking science to school: Learning and teaching science in grades $K-8$. Washington DC: The national Academies Press.

Evans, N. (1992). Experiential learning: Assessment and accreditation. London: Routledge.

Hager, P., \& Halliday, J. (2009). Recovering informal learning: Wisdom judgement and community. Amsterdam: Springer.

Hargreaves, A. (2003). Teaching in the knowledge society: Education in the age of insecurity. New York: Teachers College Press.

Harrison, M. (1954). Learning out of school. London: The Education Supply Association.

Ireland, R. D., \& Hitt, A. M. (2005). Achieving and maintaining strategic competitiveness in the 21st century: The role of strategic leadership. Academy of Management Executive, 19, 63-78. doi:10.5465/AME.2005.19417908

Jensen, L. A. (2003). Coming of age in a multicultural world: Globalization and adolescent cultural identity formation. Applied Developmental Science, 7, 189-196. doi:10.1207/S1532480XADS0703_10

Johnson, E. P., \& Chrispeels, J. H. (2010). Linking the central office and its schools for reform. Educational Administration Quarterly, 46, 738-775. doi:10.1177/0013161X10377346

Kytta, M. (2002). Affordances of children's environments in the context of cities, small towns, suburbs and rural villages in Finland and Belarus. Journal of Environmental Psychology, 22, 109-123. doi:10.1006/jevp.2001.0249

Kapur, M. (2008). Productive failure. Cognition and Instruction, 26, 379-424. doi:10.1080/07370000802212669

Lepper, M., Greene, D., \& Nisbett, R. (1973). Undermining children’s intrinsic interest with extrinsic rewards: A test of the "overjustification" hypothesis. Journal of Personality and Social Psychology, 28, 129-137. doi:10.1037/h0035519

MOE-Ministry of Education (2011a). Secondary education. URL (last checked 12 February 2012). http://www.moe.edu.gov.sg/education/secondary

MOE-Ministry of Education (2011b). Co-curricular activities. URL (last checked 12 February 2012).

http://www.moe.gov.sg/education/secondary/cca

MOE Speech (2001). URL (last checked 23 January 2012).

http://www.moe.gov.sg/media/speeches/2011/11/08/opening-address -by-mr-heng-swee-keat-at-1st-nie-moe-cce-conference.php

Mulford, B. (2008). The leadership challenge: Improving learning in schools. URL (last checked 13 December 2011). http://research.acer.edu.au/aer/2/

National Research Council (2009). Learning science in informal environments: People, places and pursuits. Washington DC: The National Academies of Press.

Nasir, N. S., \& Hand, V. (2008). From the court to the classroom: Opportunities for engagement, learning, and identity in basketball and classroom mathematics. The Journal of the Learning Sciences, 17, 143-179. doi:10.1080/10508400801986108

Ng, G. (2011). New focus on values in key education shift. URL (last checked 23 September 2011). http://www.asiaone.com/News/AsiaOne+News/Singapore/Story/A1S tory20110923-300971.html.

Thomas, G., \& Brown, S. J. (2011). A new culture of learning: Cultivating the imagination for a world of constant change. Lexington, KY: Create Space.

Shaffer, W., Squire, K., Halverson, R., \& Gee, J. P. (2005). Video games and the future of learning. Phi Delta Kappan, 87, 104-111.

The Life Center (2007). http://life-slc.org/

Winston, G. (1998). Creating the context for change. In J. Meyerson (Ed.), New thinking on higher education (pp. 1-14). Bolton, MA: Anker. 